\title{
FÁRMACOS NO MEIO AMBIENTE
}

Daniele Maia Bila e Márcia Dezotti*

COPPE, Universidade Federal do Rio de Janeiro, Cidade Universitária, Ilha do Fundão, 21945-970 Rio de Janeiro - RJ

Recebido em 29/4/02; aceito em 3/2/03

\begin{abstract}
PHARMACEUTICAL DRUGS IN THE ENVIRONMENT. Pharmaceutical drugs have been detected in sewage treatment plants, surface waters, underground waters and potable waters. Some investigations have been conducted in several countries such as Germany, Brazil, Canada, United States, The Netherlands, England and Italy. Patients and animals excrete part of pharmaceuticals used for human and veterinary medicine after administration in domestic sewage or on the soil. Drugs residues which have not been completely removed during passage through a sewage treatment plant (STP) enter the aquatic environment. The effects of such residual drugs in terrestrial and aquatic organisms are scarcely known.
\end{abstract}

Keywords: pharmaceutical drugs; water pollution; environment fate.

\section{INTRODUÇÃO}

Recentemente, o monitoramento de fármacos residuais no meio ambiente vem ganhando grande interesse devido ao fato de muitas dessas substâncias serem freqüentemente encontradas em efluentes de Estações de Tratamento de Esgoto (ETEs) e águas naturais, em concentrações na faixa de $\mu \mathrm{g} / \mathrm{L}$ e ng/L. Stumpf et al. ${ }^{1}$ relataram em seu estudo que a presença de fármacos residuais em águas superficiais pode ser um indicativo de contaminação por esgoto das ETEs.

Após a administração, uma parte significativa dos fármacos é excretada por humanos no esgoto doméstico. Estudos demostram que várias dessas substâncias parecem ser persistentes no meio ambiente e não são completamente removidas nas $\operatorname{ETEs}^{1-3}$. Sendo assim, muitos fármacos residuais resistem a vários processos de tratamento convencional de água.

Em todo mundo, fármacos, tais como, antibióticos ${ }^{4,7-10}$, hormônios $^{2,11-15}$, anestésicos ${ }^{1,2,6,16}$, antilipêmicos ${ }^{1,2,6}$, meios de contraste de raios- $\mathrm{X}^{17-19}$, antiinflamatórios ${ }^{1,2,20-22}$ entre outros, foram detectados no esgoto doméstico, em águas superficiais e de subsolo. Na Alemanha, 18 antibióticos foram identificados em efluentes de ETEs e águas superficiais por Hirsch et al. ${ }^{8}$. Ternes et al. ${ }^{3,12}$ detectaram estrogênios em concentrações na ordem de $\mu \mathrm{g} / \mathrm{L}$ em efluentes de ETEs. O ácido clofibrico, um metabólico de três antilipêmicos, foi identificado em rios, águas de subsolo e água potável na Alemanha, em concentrações na faixa de $\mu \mathrm{g} / \mathrm{L}$ por Sacher et al. ${ }^{6}$ e Ternes ${ }^{2}$.

Os fármacos são desenvolvidos para serem persistentes, mantendo suas propriedades químicas o bastante para servir a um propósito terapêutico. Porém, segundo Mulroy ${ }^{5}, 50 \%$ a $90 \%$ de uma dosagem do fármaco é excretado inalterado e persiste no meio ambiente. O uso desenfreado de antibióticos acarreta dois problemas ambientais: um, é a contaminação dos recursos hídricos e o outro, é que alguns microorganismos criam resistência a esses fármacos. As bactérias podem fazer, e freqüentemente o fazem, mudanças no seu material genético, adquirindo resistência aos fármacos. Assim, uma bactéria presente em um rio que contenha traços de antibióticos pode adquirir resistência a essas substâncias ${ }^{23}$.

De acordo com Kummerer ${ }^{24}$ alguns grupos de fármacos residuais merecem uma atenção especial, dentre eles estão os antibióticos

*e-mail: mdezotti@peq.coppe.ufrj.br e os estrogênios. Os antibióticos têm sido amplamente discutidos na literatura, devido ao seu potencial de desenvolvimento de bactérias resistentes no meio ambiente ${ }^{23,25-28}$ e por serem usados em grandes quantidades, tanto na medicina humana, quanto na medicina veterinária (crescimento do gado, na aquicultura e produção avícola e suína $)^{29-31}$.

A importância dos estrogênios reside no seu potencial de afetar adversamente o sistema reprodutivo de organismos aquáticos como, por exemplo, a feminização de peixes machos presentes em rios contaminados com descarte de efluentes de ETEs ${ }^{32-37}$.

A presença desses fármacos residuais na água pode causar efeitos adversos na saúde, seja humana ou de outros organismos presentes nas águas, como os peixes. Os efeitos causados no sistema reprodutivo de organismos aquáticos são demonstrados em alguns estudos $^{33,36,37}$. Kang et al. ${ }^{36}$ e Gimeno et al. ${ }^{37}$ examinaram o efeito do estrogênio natural $17 \beta$-estradiol no sistema reprodutor dos peixes. Sumpter $^{33}$ descreve a feminização de peixes machos expostos a estrogênios lançados nos rios através dos efluentes de ETE.

Atualmente, existe uma preocupação no desenvolvimento de métodos analíticos suficientemente sensíveis na determinação dos fármacos residuais em ambientes aquáticos, com limites de detecção na ordem de $\mu \mathrm{g} / \mathrm{L}$ e $\mathrm{ng} / \mathrm{L}^{4,6,7,38}$.

\section{OCORRÊNCIA DE FÁRMACOS EM AMBIENTES AQUÁTICOS}

Algumas toneladas de medicamentos são produzidas por ano e aplicadas na medicina humana e veterinária. Geralmente, a produção exata não é publicada na literatura.

A ocorrência de fármacos residuais no esgoto doméstico e águas naturais é um importante tópico internacional. Estudos demonstram que esses fármacos e seus metabólitos estão presentes em ambientes aquáticos em várias partes do mundo, como Alemanha ${ }^{3,4,6,10,12,18}$, Brasil $^{1,3}$, Canadá ${ }^{3,21}$, Holanda ${ }^{13}$, Inglaterra ${ }^{14}$, Itáliaa ${ }^{13,15}$, Suécia ${ }^{16,20,39}$, Estados Unidos ${ }^{9}$ e Reino Unido ${ }^{40}$.

Kolpin et al. ${ }^{9}$ detectaram antibióticos, como tetraciclinas (oxitetraciclina, tetraciclina e clorotetraciclina), sulfonamidas (sulfadimetoxina, sulfametazina, e sulfametoxazol), macrolídeos (roxitromicina, claritromicina), fluoroquinolonas (ciprofloxacina, norfloxacina), lincomicina, trimetoprim e tilosina, em amostras de águas superficiais nos Estados Unidos. 
Sacher et al. ${ }^{6}$ reportaram a ocorrência de sulfametoxazol em amostras de águas de subsolo na Alemanha. Roxitrocina, trimetoprim e sulfametoxazol foram detectados em concentrações na faixa de $\mu \mathrm{g} / \mathrm{L}$ em efluentes de ETE e águas superficiais na Alemanha por Hirsch et al. ${ }^{8}$. Hartig et al. ${ }^{10}$ detectaram antibióticos sulfonamidas (sulfadiazina, sulfametoxazol) em águas superficiais e efluentes de ETE na Alemanha.

Tanto os estrogênios naturais (estrona e 17ß-estradiol), como o sintético (17 $\alpha$-etinilestradiol) foram detectados em esgoto domésticos e efluentes de ETE em várias investigações. Ternes et al. ${ }^{3}$ identificaram a presença de vários estrogênios no esgoto doméstico e efluentes de ETE na Alemanha, Brasil e Canadá. Concluíram que esses estrogênios são freqüentemente detectados nos descartes de ETE e águas naturais devido à sua remoção incompleta na passagem pela ETE.

Investigações sobre a contaminação de diferentes ambientes aquáticos por fármacos residuais revelam que esses contaminantes estão presentes em faixas de concentrações de $\mu \mathrm{g} / \mathrm{L}$ e ng/L. A Tabela 1 apresenta um resumo das concentrações médias de fármacos detectados no meio ambiente.

\section{Fármacos residuais monitorados no Brasil}

Em 1997, antilipêmicos, antiinflamatórios e alguns metabólitos foram detectados em esgoto, em efluente de ETE e em águas de rios no estado do Rio de Janeiro por Stumpf et al. ${ }^{1}$. A concentração média, nos efluentes da ETE, da maioria dos fármacos investigados esteve na faixa de 0,1 a 1,0 $\mu \mathrm{g} / \mathrm{L}$. Nos rios, as concentrações médias situaram-se entre 0,02 e $0,04 \mu \mathrm{g} / \mathrm{L}$, como conseqüência da remoção incompleta dos fármacos durante sua passagem pela ETE e pelo descarte de esgoto in natura. A taxa de remoção de fármacos individuais durante a passagem pela ETE variou de 12 a $90 \%$.

Em outro estudo também relacionado ao Brasil, realizado por Ternes et al. ${ }^{3}$ em 1997, foram encontrados estrogênios naturais e contraceptivos sintéticos na ETE da Penha/RJ. Em esgoto bruto, os estrogênios $17 \beta$-estradiol e estrona foram detectados nas concentrações de $0,021 \mu \mathrm{g} / \mathrm{L}$ e $0,04 \mu \mathrm{g} / \mathrm{L}$, respectivamente. As taxas de remoção de estrona observadas foram de $67 \%$ para o efluente tratado em filtro biológico e $83 \%$ para o efluente tratado pelo processo de lodos ativados. Para o $17 \beta$-estradiol, estas taxas foram de 92 e 99,9\% para o efluente tratado em filtro biológico e para o efluente tratado pelo processo de lodos ativados, respectivamente. Para o estrogênio contraceptivo $17 \alpha$-etinilestradiol, as taxas de remoção na ETE foram de 64 e $78 \%$ para o efluente do filtro biológico e para o efluente do tanque de lodo ativado.

\section{DESTINO DOS FÁRMACOS NO MEIO AMBIENTE}

Geralmente, os fármacos são absorvidos pelo organismo e estão sujeitos a reações metabólicas. Entretanto, uma quantidade significativa dessas substâncias originais e seus metabólitos são excretados na urina, fezes ou esterco animal, sendo freqüentemente encontrados no esgoto doméstico.

De acordo com Richardson et $a l .^{41}$, nas ETEs há três destinos possíveis para qualquer fármaco individual:

1. pode ser biodegradável, ou seja, mineralizado a gás carbônico e água, como por exemplo, o ácido acetilsalicílico;

2. pode passar por algum processo metabólico ou ser degradado parcialmente, como as penicilinas;

3. pode ser persistente como o clofibrato, que é um antilipêmicos. Pouco se conhece sobre as rotas dos fármacos no meio ambiente. A Figura 1 apresenta um esquema que sugere possíveis caminhos para os fármacos, quando descartado no meio ambiente a $^{8,42-44}$.

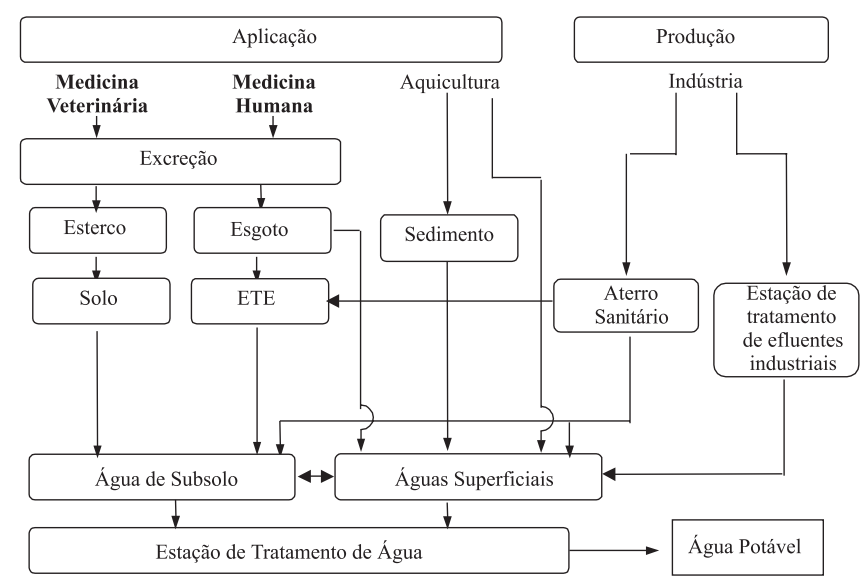

Figura 1. Possíveis rotas de fármacos no meio ambiente

Um caminho de fármacos residuais no ambiente aquático pode ser devido ao esterco ser usado como fertilizantes e, dessa forma, ocorre a contaminação das águas de subsolo. Outra contaminação pode ser devido ao uso do lodo digestivo proveniente das ETEs na agricultura.

Os antibióticos são usados como promotores de crescimento na produção de gado, na produção avícola e são intensivamente usados como aditivos de alimento de peixe na aquicultura e criação de por$\cos ^{29-31}$. Sendo assim, podem contaminar o solo, águas de subsolo e superficiais. Devido ao uso na cultura de peixes, alguns antibióticos como o cloranfenicol e o oxitetraciclina são detectados em sedimentos de origem marinha ${ }^{45,46}$.

Uma outra fonte de contaminação ambiental que tem sido observada é conseqüiente da disposição de resíduos provenientes de indústrias farmacêuticas em aterros sanitários, contaminando as águas de subsolo nas cercanias do aterro.

\section{POSSÍVEIS EFEITOS DE FÁRMACOS NO MEIO AMBIENTE}

A ocorrência de fármacos residuais no meio ambiente pode apresentar efeitos adversos em organismos aquáticos e terrestres. O efeito pode ser em qualquer nível da hierarquia biológica: célula - órgãos - organismo - população - ecossistema. De acordo com Jorgensen et $a l .{ }^{43}$, alguns desses efeitos podem ser observados em concentrações na ordem de ng/L. Pouco é conhecido sobre o destino e o comportamento dessas substâncias no ambiente aquático, assim como não está claro quais organismos são afetados e em que grau.

Os antibióticos têm diferentes efeitos sobre o meio ambiente, e um deles é a contribuição no desenvolvimento de bactérias resistentes, assunto que tem sido largamente discutido ${ }^{27,28,47-53}$. Segundo Jorgensen et $a l .^{42}$, há indícios de que o desenvolvimento de resistência antibiótica é favorecido por baixas concentrações.

Miranda et al. ${ }^{28}$ investigaram a incidência de resistência microbiana em uma espécie de Aeromonas isolada de ambientes aquáticos, constatando que a resistência ocorreu com vários antibióticos testados, dentre esses, cloranfenicol, trimetropim, sulfametoxazol e tetraciclina.

Kolár et al..$^{48}$ avaliaram o desenvolvimento da resistência bacteriana aos antibióticos usados em hospitais, os quais são poderosos focos de desenvolvimento de resistência bacteriana. Mckeon et $a l .^{27}$ constataram a resistência bacteriana da espécie Escherichia coli, isolada de águas de subsolo de uma região rural, frente a 16 antibióticos. 
Tabela 1. Concentrações médias de fármacos detectados no meio ambiente

\begin{tabular}{|c|c|c|c|c|}
\hline Substâncias & Classe das Substâncias & $\begin{array}{c}\text { Concentrações médias } \\
\text { no ambiente }\end{array}$ & Condições & Referência \\
\hline Ácido Acetilsalicílico & Analgésico & $0,22 \mu \mathrm{g} / \mathrm{L}$ & Efluente de ETE/Alemanha & 2 \\
\hline \multirow[t]{7}{*}{ Ácido Clofibrico } & Maior metabólico de & $0,36 \mu \mathrm{g} / \mathrm{L}$ & Efluente de ETE/Alemanha & 2 \\
\hline & 3 antilipêmicos & $0,066 \mu \mathrm{g} / \mathrm{L}$ & Água superficial/Alemanha & 2 \\
\hline & & $1,0 \mu \mathrm{g} / \mathrm{L}$ & Esgoto doméstico/Brasil & 1 \\
\hline & & 0,02 a $0,03 \mu \mathrm{g} / \mathrm{L}$ & Água superficial/Brasil & 1 \\
\hline & & $0,049 \mu \mathrm{g} / \mathrm{L}$ & Água superficial/Canadá & 21 \\
\hline & & $0,01-18 \mathrm{ng} / \mathrm{L}$ & Água superficial/Mar do Norte & 22 \\
\hline & & $1-9 \mathrm{ng} / \mathrm{L}$ & Água superficial/Suécia & 39 \\
\hline \multirow[t]{2}{*}{ Ácido Fenofibrico } & Maior metabólico de & $0,38 \mu \mathrm{g} / \mathrm{L}$ & Efluente de ETE/Alemanha & 2 \\
\hline & 3 antilipêmicos & $0,45 \mu \mathrm{g} / \mathrm{L}$ & Água superficial/Alemanha & 2 \\
\hline Betaxolol & $\beta$-bloqueador & $0,057 \mu \mathrm{g} / \mathrm{L}$ & Efluente de ETE/Alemanha & 2 \\
\hline Bisoprolol & $\beta$-bloqueador & $0,057 \mu \mathrm{g} / \mathrm{L}$ & Efluente de ETE/Alemanha & 2 \\
\hline \multirow{3}{*}{ Bezafibrato } & Antilipêmicos & $2,2 \mu \mathrm{g} / \mathrm{L}$ & Efluente de ETE/Alemanha & 2 \\
\hline & & $0,35 \mu \mathrm{g} / \mathrm{L}$ & Água superficial/Alemanha & 2 \\
\hline & & $1,2 \mu \mathrm{g} / \mathrm{L}$ & Esgoto doméstico/Brasil & 1 \\
\hline \multirow[t]{2}{*}{ Bezafibrato } & Antilipêmicos & $1,0 \mu \mathrm{g} / \mathrm{L}$ & Efluente de ETE/Brasil & 1 \\
\hline & & $0,025 \mu \mathrm{g} / \mathrm{L}$ & Água superficial/Brasil & 1 \\
\hline \multirow[t]{2}{*}{ Carbamazepina } & Anticonvulsivante & $2,1 \mu \mathrm{g} / \mathrm{L}$ & Efluente de ETE/Alemanha & 2 \\
\hline & & $0,25 \mu \mathrm{g} / \mathrm{L}$ & Água superficial/Alemanha & 2 \\
\hline Cetoprofeno & Antiinflamatório & $0,20 \mu \mathrm{g} / \mathrm{L}$ & Efluente de ETE/Alemanha & 2 \\
\hline Ciprofloxacin & Antibiótico & $0,02 \mu \mathrm{g} / \mathrm{L}$ & Água natural/EUA & 9 \\
\hline Clorotetraciclina & Antibiótico & $0,42 \mu \mathrm{g} / \mathrm{L}$ & Água natural/EUA & 9 \\
\hline \multirow[t]{2}{*}{ Diazepam } & Droga Psiquiátrica & $0,033 \mu \mathrm{g} / \mathrm{L}$ & Efluente de ETE/Alemanha & 7 \\
\hline & & $0,053 \mu \mathrm{g} / \mathrm{L}$ & Água superficial/Alemanha & 7 \\
\hline \multirow[t]{6}{*}{ Diclofenaco } & Antiinflamatório & 0,02 a $0,06 \mu \mathrm{g} / \mathrm{L}$ & Água superficial/Brasil & 1 \\
\hline & & $0,81 \mu \mathrm{g} / \mathrm{L}$ & Efluente de ETE/Alemanha & 2 \\
\hline & & $0,15 \mu \mathrm{g} / \mathrm{L}$ & Água superficial/Alemanha & 2 \\
\hline & & $200-370 \mathrm{ng} / \mathrm{L}$ & Efluente de ETE/Suécia & 16 \\
\hline & & $<1-12 \mathrm{ng} / \mathrm{L}$ & Água superficial/Suécia & 16 \\
\hline & & $6,2 \mathrm{ng} / \mathrm{L}$ & Água superficial/Mar do Norte & 22 \\
\hline \multirow[t]{3}{*}{ Eritromicina } & Antibiótico & $0,1 \mu \mathrm{g} / \mathrm{L}$ & Água natural/EUA & 9 \\
\hline & & $0,15 \mu \mathrm{g} / \mathrm{L}$ & Água superficial/Alemanha & 8 \\
\hline & & $2,5 \mu \mathrm{g} / \mathrm{L}$ & Efluente de ETE/Alemanha & 8 \\
\hline \multirow[t]{11}{*}{$17 \alpha$-Etinilestradiol } & Hormônio & $0,005 \mu \mathrm{g} / \mathrm{L}$ & Esgoto doméstico/Brasil & 3 \\
\hline & & $0,001 \mu \mathrm{g} / \mathrm{L}$ & Efluente de ETE/Alemanha & 3 \\
\hline & & $0,45 \mu \mathrm{g} / \mathrm{L}$ & Água superficial/Alemanha & 3 \\
\hline & & $0,009 \mu \mathrm{g} / \mathrm{L}$ & Efluente de ETE/Canadá & 3 \\
\hline & & $0,073 \mu \mathrm{g} / \mathrm{L}$ & Água natural/EUA & 9 \\
\hline & & $<0,5-10 \mathrm{ng} / \mathrm{L}$ & Esgoto doméstico/Itália e Holanda & 13 \\
\hline & & $<0,2-2,2 \mathrm{ng} / \mathrm{L}$ & Efluente de ETE/Itália e Holanda & 13 \\
\hline & & $0,2-7,0 \mathrm{ng} / \mathrm{L}$ & Efluente de ETE/Inglaterra & 14 \\
\hline & & $0,3-1,7 \mathrm{ng} / \mathrm{L}$ & Efluente de ETE/Itália & 15 \\
\hline & & $4,5 \mathrm{ng} / \mathrm{L}$ & Esgoto doméstico/Suécia & 72 \\
\hline & & $2 \mathrm{ng} / \mathrm{L}$ & Efluente de ETE/Suécia & 72 \\
\hline \multirow[t]{5}{*}{$17 \beta$-Estradiol } & Hormônio & $0,015 \mu \mathrm{g} / \mathrm{L}$ & Esgoto doméstico/Alemanha & 3 \\
\hline & & $0,006 \mu \mathrm{g} / \mathrm{L}$ & Efluente de ETE/Canadá & 3 \\
\hline & & $0,021 \mu \mathrm{g} / \mathrm{L}$ & Esgoto doméstico/Brasil & 3 \\
\hline & & $0,009-0,16 \mu \mathrm{g} / \mathrm{L}$ & Água natural/EUA & 9 \\
\hline & & $2-12 \mu \mathrm{g} / / \mathrm{mulher} / \mathrm{dia}$ & $\begin{array}{l}\text { Naturalmente excretado por } \\
\text { uma mulher por dia }\end{array}$ & 11 \\
\hline
\end{tabular}


Tabela 1. continuação

\begin{tabular}{|c|c|c|c|c|}
\hline Substâncias & Classe das Substâncias & $\begin{array}{c}\text { Concentrações médias } \\
\text { no ambiente }\end{array}$ & Condições & Referência \\
\hline $17 \beta$-Estradiol & Hormônio & $\begin{array}{c}<0,5-17 \mathrm{ng} / \mathrm{L} \\
<0,5-7 \mathrm{ng} / \mathrm{L} \\
2,7-48 \mathrm{ng} / \mathrm{L} \\
1,1 \mathrm{ng} / \mathrm{L} \\
0,5 \mathrm{ng} / \mathrm{L}\end{array}$ & $\begin{array}{l}\text { Esgoto doméstico/Itália e Holanda } \\
\text { Efluente de ETE/Itália e Holanda } \\
\text { Efluente de ETE/Inglaterra } \\
\text { Esgoto doméstico/Suécia } \\
\text { Efluente de ETE/Suécia }\end{array}$ & $\begin{array}{l}13 \\
13 \\
14 \\
72 \\
72\end{array}$ \\
\hline Estrona & Hormônio & $\begin{array}{c}0,02 \text { a } 0,05 \mu \mathrm{g} / \mathrm{L} \\
0,04 \mu \mathrm{g} / \mathrm{L} \\
0,027 \mu \mathrm{g} / \mathrm{L} \\
0,009 \mu \mathrm{g} / \mathrm{L} \\
0,003 \mu \mathrm{g} / \mathrm{L} \\
0,7-1,6 \mathrm{ng} / \mathrm{L} \\
0,027 \mu \mathrm{g} / \mathrm{L} \\
<0,5-38 \mathrm{ng} / \mathrm{L} \\
<0,5-54 \mathrm{ng} / \mathrm{L} \\
20-132 \mathrm{ng} / \mathrm{L} \\
2,5-82,1 \mathrm{ng} / \mathrm{L}\end{array}$ & $\begin{array}{l}\text { Água superficial/Brasil } \\
\text { Esgoto doméstico/Brasil } \\
\text { Esgoto doméstico/Alemanha } \\
\text { Efluente de ETE/Alemanha } \\
\text { Efluente de ETE no Canadá } \\
\text { Água superficial/Alemanha } \\
\text { Água natural/EUA } \\
\text { Esgoto doméstico/Itália e Holanda } \\
\text { Efluente de ETE/Itália e Holanda } \\
\text { Esgoto doméstico/Itália } \\
\text { Efluente de ETE/Itália }\end{array}$ & $\begin{array}{c}3 \\
3 \\
3 \\
3 \\
3 \\
3 \\
9 \\
13 \\
13 \\
15 \\
15\end{array}$ \\
\hline Estrona & Hormônio & $\begin{array}{c}6,4-29 \mathrm{ng} / \mathrm{L} \\
0,2-17 \mathrm{ng} / \mathrm{L} \\
5,8 \mathrm{ng} / \mathrm{L} \\
0,5 \mathrm{ng} / \mathrm{L}\end{array}$ & $\begin{array}{l}\text { Efluente de ETE/Alemanha } \\
\text { Água natural/Inglaterra } \\
\text { Esgoto doméstico/Suécia } \\
\text { Efluente de ETE/Suécia }\end{array}$ & $\begin{array}{l}40 \\
40 \\
72 \\
72\end{array}$ \\
\hline Estriol & Hormônio & $\begin{array}{c}2-4 \mathrm{ng} / \mathrm{L} \\
1,2-3,1 \mathrm{ng} / \mathrm{L} \\
24-188 \mathrm{ng} / \mathrm{L} \\
0,43-18 \mathrm{ng} / \mathrm{L} \\
0,019 \mu \mathrm{g} / \mathrm{L}\end{array}$ & $\begin{array}{l}\text { Efluente de ETE/Inglaterra } \\
\text { Água natural/Inglaterra } \\
\text { Esgoto doméstico/Itália } \\
\text { Efluente de ETE/Itália } \\
\text { Água natural/EUA }\end{array}$ & $\begin{array}{l}40 \\
40 \\
15 \\
15 \\
9\end{array}$ \\
\hline Indometacina & Antiinflamatório & $\begin{array}{l}0,95 \mu \mathrm{g} / \mathrm{L} \\
0,27 \mu \mathrm{g} / \mathrm{L} \\
0,17 \mu \mathrm{g} / \mathrm{L}\end{array}$ & $\begin{array}{l}\text { Esgoto doméstico/Brasil } \\
\text { Efluente de ETE/Alemanha } \\
\text { Águas superficial/Alemanha }\end{array}$ & $\begin{array}{l}2 \\
2 \\
2\end{array}$ \\
\hline Iopamidol & Meio de contraste de Raios-X & $\begin{array}{c}4,3 \pm 0,9 \mu \mathrm{g} / \mathrm{L} \\
0,66 \mu \mathrm{g} / \mathrm{L} \\
0,49 \mu \mathrm{g} / \mathrm{L}\end{array}$ & $\begin{array}{l}\text { Esgoto doméstico/Alemanha } \\
\text { Efluente de ETE/Alemanha } \\
\text { Água superficial/Alemanha }\end{array}$ & $\begin{array}{l}18 \\
18 \\
18\end{array}$ \\
\hline Iopromida & Meio de contraste de Raios-X & $\begin{array}{c}7,5 \pm 1,5 \mu \mathrm{g} / \mathrm{L} \\
0,75 \mu \mathrm{g} / \mathrm{L} \\
0,10 \mu \mathrm{g} / \mathrm{L}\end{array}$ & $\begin{array}{l}\text { Esgoto doméstico/Alemanha } \\
\text { Efluente de ETE/Alemanha } \\
\text { Água superficial/Alemanha }\end{array}$ & $\begin{array}{l}18 \\
18 \\
18\end{array}$ \\
\hline Iopromida & Meio de contraste de Raios-X & $1,6 \mu \mathrm{g} / \mathrm{L}$ & Água superficial/Alemanha & 19 \\
\hline Iomeprol & Meio de contraste de Raios-X & $\begin{array}{c}1,6 \pm 0,4 \mu \mathrm{g} / \mathrm{L} \\
0,37 \mu \mathrm{g} / \mathrm{L} \\
0,10 \mu \mathrm{g} / \mathrm{L}\end{array}$ & $\begin{array}{l}\text { Esgoto doméstico/Alemanha } \\
\text { Efluente de ETE/Alemanha } \\
\text { Água superficial/Alemanha }\end{array}$ & $\begin{array}{l}18 \\
18 \\
18\end{array}$ \\
\hline Ibuprofeno & Antiinflamatório & $\begin{array}{c}0,087 \mu \mathrm{g} / \mathrm{L} \\
0,07 \mu \mathrm{g} / \mathrm{L} \\
0,37 \mu \mathrm{g} / \mathrm{L} \\
0,01 \mu \mathrm{g} / \mathrm{L} \\
1-3,3 \mu \mathrm{g} / \mathrm{L} \\
2-81 \mathrm{ng} / \mathrm{L} \\
1,5-7,8 \mathrm{ng} / \mathrm{L}\end{array}$ & $\begin{array}{l}\text { Água superficial/Canadá } \\
\text { Águas superficiais/Alemanha } \\
\text { Efluente de ETE/Alemanha } \\
\text { Águas superficiais/Brasil } \\
\text { Esgoto doméstico/Suécia } \\
\text { Efluente de ETE/ Suécia } \\
\text { Água superficial/ Suécia }\end{array}$ & $\begin{array}{c}21 \\
2 \\
2 \\
1 \\
20 \\
20 \\
20\end{array}$ \\
\hline Lincomicina & Antibiótico & $0,06 \mu \mathrm{g} / \mathrm{L}$ & Água natural/EUA & 9 \\
\hline Norfloxacina & Antibiótico & $0,12 \mu \mathrm{g} / \mathrm{L}$ & Água natural/EUA & 9 \\
\hline Oxitetraciclina & Antibiótico & $0,34 \mu \mathrm{g} / \mathrm{L}$ & Água natural/EUA & 9 \\
\hline Penicilina & Antibiótico & 1,8 a $5,9 \mathrm{ng} / \mathrm{L}$ & Água superficial/Alemanha & 5 \\
\hline Progesterona & Hormônio & $0,11 \mu \mathrm{g} / \mathrm{L}$ & Água natural/EUA & 9 \\
\hline Propanolol & $\beta$-bloqueador & $\begin{array}{l}0,17 \mu \mathrm{g} / \mathrm{L} \\
0,012 \mu \mathrm{g} / \mathrm{L}\end{array}$ & $\begin{array}{l}\text { Efluente de ETE/Alemanha } \\
\text { Água superficial/Alemanha }\end{array}$ & $\begin{array}{l}2 \\
2\end{array}$ \\
\hline
\end{tabular}


Tabela 1. continuação

\begin{tabular}{llcl}
\hline Substâncias & Classe das Substâncias & $\begin{array}{c}\text { Concentrações médias } \\
\text { no ambiente }\end{array}$ & Condições \\
\hline Roxitrocina & Antibiótico & $0,05 \mu \mathrm{g} / \mathrm{L}$ & Água natural/EUA \\
& & $0,68-1,0 \mu \mathrm{g} / \mathrm{L}$ & $\begin{array}{c}\text { Efluente de ETE/Alemanha } \\
\text { Água superficial/Alemanha }\end{array}$ \\
\hline Sulfametoxazol & Antibiótico & $0,56 \mu \mathrm{g} / \mathrm{L}$ & 9 \\
& & $30-85 \mathrm{ng} / \mathrm{L}$ & Água superficial/Alemanha \\
& & $300 \pm 12-1500 \pm 320 \mathrm{ng} / \mathrm{L}$ & Efluente de ETE/Alemanha \\
& $0,006-0,15 \mu \mathrm{g} / \mathrm{L}$ & Água natural/EUA & Água de subsolo/Alemanha \\
& & $410 \mathrm{ng} / \mathrm{L}$ & Efluente de ETE/Alemanha \\
& & $0,4 \mu \mathrm{g} / \mathrm{L}$ & Água superficial/Alemanha \\
\hline Testosterona & $0,03 \mu \mathrm{g} / \mathrm{L}$ & Água natural/EUA \\
\hline Tetraciclina & Hormônio & $0,116 \mu \mathrm{g} / \mathrm{L}$ & Água natural/EUA \\
& Antibiótico & $0,11 \mu \mathrm{g} / \mathrm{L}$ & Água superficial/Alemanha \\
\hline Trimetoprim & & $1,2 \mathrm{a} 4,2 \mu \mathrm{g} / \mathrm{L}$ & 8 \\
& Antibiótico & $0,013-0,15 \mu \mathrm{g} / \mathrm{L}$ & Água natural/EUA \\
& & $0,32-0,66 \mu \mathrm{g} / \mathrm{L}$ & Efluente de ETE/Alemanha \\
& & $2,5 \mu \mathrm{g} / \mathrm{L}$ & Efluente de ETE/Alemanha \\
\hline Tilosina & $0,15 \mu \mathrm{g} / \mathrm{L}$ & Água superficial/Alemanha \\
\hline Vancomicina & Antibiótico & $0,04 \mu \mathrm{g} / \mathrm{L}$ & Água natural/EUA
\end{tabular}

Estudos sobre os efeitos causados ao meio ambiente com o uso de antibióticos na aquicultura foram desenvolvidos por vários pesquisadores ${ }^{45,46,54}$. Um desses efeitos descreve o desenvolvimento de uma população de bactérias resistentes em sedimentos marinhos ${ }^{54}$. $\mathrm{O}$ estudo de $\mathrm{Wu}^{54}$ mostrou que o maior impacto é no sedimento marinho, e em menor extensão na qualidade da água.

Recentemente, alguns pesquisadores investigaram um grupo específico de compostos químicos presentes no meio ambiente que são responsáveis por causar perturbações no sistema endócrino (hormonal) de organismos humanos e animais: são os chamados perturbadores endócrinos. Dentre esse grupo de substâncias estão os estrogênios naturais e contraceptivos ${ }^{3,11,12}$.

Alguns autores relatam que, dependendo da dose e do tempo de exposição, é possível que essas substâncias estejam relacionadas com doenças como câncer de mama, testicular e de próstata, ovários policísticos e redução da fertilidade masculina $a^{55-57}$.

As evidências mostram que os sistemas reprodutivos de certos organismos terrestres e aquáticos são afetados por estrogênios, resultando no desenvolvimento de anormalidades e deterioração reprodutiva nos organismos expostos ${ }^{58-61}$. Conseqüentemente, numerosos testes e biomarcadores têm sido desenvolvidos para detectar a atividade estrogênica dessas substâncias ${ }^{34,35,55,62}$.

Um marcador bastante usado para a determinação da atividade estrogênica de uma substância é a determinação de níveis de vitelogenina (VTG) no plasma sangüíneo de um organismo ${ }^{63,64}$. Vitelogenina é uma proteína que desempenha um importante papel no sistema reprodutivo de vertebrados ovíparos fêmeas. É sintetizada no fígado, regulada por estrogênio e transportada através do sangue para os ovários, onde serão incorporados no desenvolvimento dos óvulos ${ }^{64-66}$. De um modo geral, o gene do VTG também está presente em organismos machos, mas sob condições normais não é expressivo, possivelmente, pela baixa concentração de estrogênio no sangue ${ }^{63}$. $\mathrm{O}$ aumento de VTG no plasma de um organismo é considerada uma evidência da exposição a substâncias com atividade estrogênica ${ }^{13,66}$.

As conseqüências da presença de estrogênios em organismos aquáticos, em concentrações ambientalmente relevantes, não são com- pletamente conhecidas. Entretanto, tem sido observado que alguns organismos aquáticos respondem com um aumento na síntese de VTG como resposta à exposição a determinadas concentrações de estrogênio ${ }^{67,68}$. Além disso, essa exposição a estrogênios pode causar a feminização de peixes se a exposição ocorrer durante o período crítico da diferenciação sexual. Isso foi observado em espécies de peixes, como Cyprinus carpio ${ }^{69}$ e Rutilus rutilus ${ }^{70}$. Efeitos similares (indução do hermafroditismo ou a feminização completa) foram também observados quando peixes da espécie Oryzias latipes foram expostos ao estrogênio $17 \beta$-estradiol ${ }^{59,71}$.

Larsson et $_{\text {al. }}{ }^{72}$ analisaram a atividade estrogênica do efluente de uma ETE na Suécia, pela quantificação de VTG no plasma de uma espécie de peixe, Oncorhunchus mykiss, que foi exposta a este efluente por duas semanas.

Gagné et al. $^{73}$ examinaram o efeito da atividade estrogênica dos efluentes de ETE sobre mexilhões da espécie Elliptio complanata proveniente de águas naturais. Os mexilhões foram expostos a um efluente de ETE por aproximadamente dois meses. Os autores observaram um aumento dos níveis de VTG em mexilhões machos e fêmeas, além de anomalias no crescimento da concha dos mexilhões.

Em um experimento com tartarugas da espécie Chrysemys picta, Irwin et al. ${ }^{65}$ mostraram que as tartarugas fêmeas expostas a estrogênios são afetadas com altos níveis de VTG no plasma. Esses altos níveis de VTG podem alterar o sistema reprodutivo desses animais como, por exemplo, por alterações na produção de ovos.

No estudo de Routledge et al..$^{74}$, duas espécies de peixes Oncorhynchus mykiss e Rutilus rutilus - foram expostas por 21 dias a concentrações de $17 \beta$-estradiol e estrona ambientalmente relevantes. De acordo com esses pesquisadores, os resultados confirmaram que os estrogênios identificados em efluentes domésticos estão presentes em quantidades suficientes para causar a síntese de VTG nas espécies de peixes estudadas.

Os peixes são um dos grupos de organismos mais completamente estudados em termos de efeito de substâncias com atividade estrogênica no desenvolvimento de anomalias no sistema reprodutivo. De acordo com Sumpter ${ }^{33}$, as pesquisas de como substâncias estro- 
gênicas afetam o sistema sexual dos peixes começaram na década de 1980.

Kang et $a l .{ }^{36}$ mostram claramente que a exposição a concentrações do estrogênio $17 \beta$-estradiol ambientalmente relevantes (na faixa de 30-500 ng/L), por três semanas, induz a concentrações elevadas de VTG e à incidência de hermafroditismo em peixes machos da espécie Oryzias latipes.

No estudo de Rodgres-Gray et al..$^{75}$, peixes jovens da espécie Rutilus rutilus foram expostos a concentrações gradativas de efluente de ETE por 150 dias. Os resultados mostraram que a exposição induziu a feminização de peixes machos. Subseqüentemente, os peixes foram gradativamente expostos a águas naturais por mais 150 dias, resultando na redução de VTG no plasma, porém, não se observou alteração no sistema sexual feminizado dos peixes, indicando que o desenvolvimento da anomalia no sistema reprodutivo foi permanente.

De acordo com estudos de Panter et al. ${ }^{64}$, concentrações baixas de $17 \beta$-estradiol e estrona, similares às concentrações encontradas em efluentes, causaram profundos efeitos em peixes machos da espécie Pimephales promelas. Os efeitos relatados foram a síntese de VTG e a inibição testicular, quando expostos a concentrações de $17 \beta$-estradiol $(10,32,100,320$ e $1000 \mathrm{ng} / \mathrm{L})$ e estrona $(9,9,31,8$, 99,3, 318, 993 ng/L). Outros estudos ${ }^{61,63,76}$ também observaram a síntese de VTG na exposição da espécie de peixe Pimephales promelas a substâncias com atividade estrogênica.

No estudo de Folmar et al. ${ }^{55}$, as menores concentrações de substâncias com atividade estrogênica que induziram a síntese de VTG em uma população de peixes machos da espécie Cyorinodon variegatus foram de $200 \mathrm{ng} / \mathrm{L}$ para o $17 \beta$-estradiol e de $100 \mathrm{ng} / \mathrm{L}$ para o $17 \alpha$-etinilestradiol.

Embora as concentrações desses hormônios nos efluentes sejam baixas (da ordem de ng/L e $\mu \mathrm{g} / \mathrm{L}$ ), estas são suficientemente elevadas para induzir a síntese de VTG em peixes machos em experimentos de laboratório como descrito nos vários estudos citados anteriormente.

Legler et $a l .{ }^{33}$ demonstraram que as substâncias estrogênicas não só são importantes na fase aquosa, mas também podem se acumular em sedimentos marinhos e assim afetar os organismos presentes no meio. Porém, pouco é conhecido sobre a exposição de organismos em ambientes aquáticos a substâncias estrogênicas presentes em sedimentos marinhos.

Pelo número de estudos nesta área, fica evidente que a exposição a substâncias com atividade estrogênica no meio ambiente é um problema de saúde ambiental global. Essas anomalias têm sido atribuídas à presença de substâncias estrogênicas em ambientes aquáticos e são associadas ao descarte de efluentes de ETE em corpos receptores.

Atualmente, dois tópicos sobre o efeito desses fármacos no meio ambiente são os mais discutidos. O desenvolvimento de resistência bacteriana aos antibióticos ${ }^{12,27,28,51-52,77,78}$ e avaliações de perturbações no sistema endócrino por substâncias como estrogênios ${ }^{32,33,36,37}$. Outros efeitos possíveis têm sido pouco discutidos.

\section{MÉTODOS ANALÍTICOS UTILIZADOS NA DETERMINAÇÃO DE FÁRMACOS}

Para a determinação de fármacos, diferentes métodos analíticos são reportados na literatura, os quais são principalmente válidos para matrizes biológicas como sangue, tecido e urina ${ }^{79-81}$, sendo que algumas modificações nestes métodos podem ser suficientes para amostras ambientais. No entanto, a análise de fármacos residuais em efluentes de ETE, em águas de rios, de subsolos e água potável requer ainda o desenvolvimento de métodos mais sensíveis para a detecção de concentrações na faixa de $\mu \mathrm{g} / \mathrm{L}$ e ng/L.

Nos últimos anos, muitos métodos para a análise de fármacos em amostras de águas foram publicados, tais como para antilipêmicos, $\beta$-bloqueadores e antiinflamatórios e alguns na determinação de antibióticos, estrogênios e drogas psiquiátricas. Ternes ${ }^{38}$ em seu estudo fez uma revisão de todos os métodos analíticos utilizados na determinação de vários fármacos residuais, a níveis de ng/L, em diferentes matrizes aquosas.

Para detecção de fármacos residuais em ambiente aquático na faixa de $\mu \mathrm{g} / \mathrm{L}$ e ng/L, os métodos descritos na literatura são baseados na extração em fase sólida, em alguns casos derivatização da substância ácida e subseqüente determinação do derivado por cromatografia gasosa acoplada à espectrometria de massas (CG/EM) ou cromatografia líquida de alta eficiência acoplada a espectrometria de massas (CLAE/EM). A detecção por espectrometria de massas é usada para assegurar a identificação das substâncias estudadas.

A Tabela 2 apresenta as diferentes técnicas utilizadas na detecção de fármacos em amostras de ambientes aquáticos.

\section{AVALIAÇÃO DO IMPACTO AMBIENTAL DE FÁRMACOS EM AMBIENTES AQUÁTICOS}

No momento, um ponto crítico neste tema é saber se existe um nível elevado dessas substâncias no meio ambiente, que sejam suficientes para exercer efeitos adversos em seres vivos. Esta questão estimula o desenvolvimento de estudos de impacto ambiental causado por diferentes fármacos presentes no meio ambiente. Dados ecotoxicológicos têm sido levantados por pesquisadores, para se identificar fármacos que são potencialmente perigosos para o meio ambiente, porém, os dados disponíveis na literatura são insuficientes. A ocorrência desses fármacos residuais em águas superficiais e de subsolo demonstra uma necessidade de estudos que determinem os efeitos tóxicos desses fármacos frente ao meio ambiente.

Neste contexto, alguns pesquisadores analisam riscos em potencial para alguns fármacos no meio ambiente. Henschel et al. ${ }^{90}$ analisaram dois fármacos, o paracetamol e o metotrexate, e dois metabólitos, o ácido salicílico e o ácido clofibrico, com relação às suas biodegradabilidades e testes de toxicidade (valores de $\mathrm{CE}_{50}$ com algas, microcrustáceo da espécie Daphnia magma, embriões de peixe e bactérias luminescentes).

Os dados dos efeitos tóxicos $\left(\mathrm{CE}_{50}\right)$ de alguns antibióticos em várias espécies aquáticas podem ser encontrados na literatura ${ }^{91-94}$.

Wollenberger et al..$^{94}$ investigaram as toxicidades aguda e crônica com o microcrustáceo da espécie Daphnia magma para nove antibióticos, dentre esses, oxitetraciclina, sulfadiazina, tetraciclina e tilosina.

Outros estudos ${ }^{42,95,96}$ avaliaram o potencial de impacto do lançamento de fármacos no meio ambiente, com estudos sobre o destino ambiental e efeitos causados em organismos aquáticos. StuerLauridsen et al. ${ }^{97}$ realizaram estudo de análise de risco ambiental dos 20 fármacos mais usados na Dinamarca, dentre esses, analgésicos, estrogênios e antiinflamatórios. No estudo de Jones et al..$^{8}$ foi apresentada a análise de risco ambiental para os 25 fármacos mais usados na Inglaterra.

Os efeitos tóxicos de fármacos residuais têm sido avaliados utilizando uma biota aquática, no entanto, poucos dados experimentais têm sido obtidos para comunidades terrestres. Como exemplo, o estudo desenvolvido por Migliore et al. ${ }^{99}$ avaliou os efeitos do antibiótico sulfonamida na contaminação de um sistema terrestre com três espécies de plantas, fornecendo informações da alteração no desenvolvimento normal, crescimento e a bioacumulação em diferentes compartimentos da planta. Outros problemas observados foram a modificação da comunidade microbiana do solo, incluindo o desenvolvimento de resistência bacteriana e a inibição do mecanismo natural de descontaminação para pesticidas e outros xenobióticos.

Alguns pesquisadores vêm avaliando os possíveis riscos ambientais causados por medicamentos veterinários, por exemplo, aqueles 
Tabela 2. Métodos utilizados na determinação de fármacos no ambiente aquático

\begin{tabular}{|c|c|c|}
\hline Método & Substâncias & Referência \\
\hline \multirow[t]{3}{*}{ CLAE/EM ${ }^{\mathrm{a}}$} & Ácido salicílico, antiinflamatórios e antilpêmicos & 82 \\
\hline & Ácido clofibrico, antibióticos, antilpêmicos, antiinflamatórios, anticonvulsivantes & 83 \\
\hline & Antibióticos & 84 \\
\hline \multirow[t]{5}{*}{ CLAE/EM/EM ${ }^{\mathrm{b}}$} & Antibióticos & 4 \\
\hline & Analgésicos, $\beta$-bloqueadores, antilpêmicos, antibióticos & 6 \\
\hline & Antiinflamatórios, drogas psiquiátricas e antidiabéticas & 7 \\
\hline & $\beta$-bloqueadores, antibióticos & 38 \\
\hline & Antibióticos & 85 \\
\hline \multirow[t]{4}{*}{$\mathrm{CG} / \mathrm{EM}^{\mathrm{c}}$} & Analgésicos, antilpêmicos e metabólitos, antiinflamatórios. & 1 \\
\hline & $\begin{array}{l}\text { Analgésicos, antipiréticos, antiinflamatórios, antilpêmicos, anticonvulsivantes, } \\
\text { drogas psiquiátricas }\end{array}$ & 6 \\
\hline & Estrogênios & 40,86 \\
\hline & Ácido Clofibrico, antiinflamatórios, anticonvulsivantes & 87 \\
\hline \multirow[t]{2}{*}{ CG-EM/EM ${ }^{\mathrm{d}}$} & $\begin{array}{l}\text { Antiinflamatórios, anticonvulsivantes, ácido salicílico, ácido clofibrico, antilpêmicos, } \\
\beta \text {-bloqueadores, drogas psiquiátricas, estrogênios }\end{array}$ & 38 \\
\hline & Estrogênios & $3,12,88,89$ \\
\hline
\end{tabular}

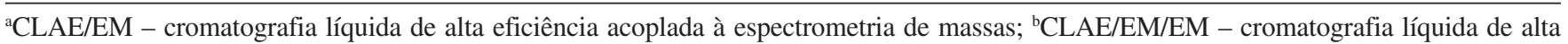
eficiência acoplada a dois espectrômetros de massas em série; ${ }^{\mathrm{C}} \mathrm{CG} / \mathrm{EM}$-cromatografia gasosa acoplada a espectrometria de massas; ${ }^{\mathrm{d} C G}$-EM/ EM - cromatografia gasosa acoplada a dois espectrômetros de massas em série

usados na criação de gado, no solo, nas águas superficiais e de subsolo. Boxall et al. ${ }^{1{ }^{100}}$ investigaram a adsorção de antibióticos e sulfanamidas pelo solo e o potencial dessas substâncias em serem transportadas para as águas de subsolo e superficiais.

Atualmente, uma avaliação de risco ambiental devido à contaminação por fármacos tem sido requerida em vários países ${ }^{96}$. Com isso, vários pesquisadores vêm desenvolvendo metodologias de testes ecotoxicológicos e modelos para avaliação de risco ambiental para alguns fármacos de uso veterinário ${ }^{101}$.

\section{CONCLUSÃO}

Atualmente, há uma crescente preocupação com a presença de fármacos em ambientes aquáticos e seus possíveis impactos ambientais. A literatura mostra que vários pesquisadores, em todo o mundo, detectaram muitos desses fármacos residuais em águas naturais e em efluentes de ETEs.

Pesquisadores desenvolveram e vem desenvolvendo métodos cromatográficos para a identificação e quantificação de fármacos em efluentes de ETEs e águas naturais, em baixas concentrações.

Pouco é conhecido sobre o efeito dessas substâncias no meio ambiente. Outro ponto pouco explorado refere-se a uma avaliação de impacto no meio ambiente através de dados ecotoxicológicos.

É necessária uma avaliação criteriosa dos efeitos desses fármacos no meio aquático. Uma vez conhecido os efeitos, será necessário estabelecer os limites de concentrações para o descarte seguro de efluentes domésticos tratados em corpos receptores. O monitoramento da eficiência de remoção desses fármacos pelos processos convencionais de tratamento de efluentes domésticos das ETEs é de grande importância pois, no futuro, podem ser necessárias adaptações, ou mesmo implantar outros processos de tratamento que complementem a remoção adequada desses fármacos.

\section{REFERÊNCIAS}

1. Stumpf, M.; Ternes, T. A.; Wilken, R.; Rodrigues, S. V.; Baumann, W.; Sci. Total Environ. 1999, 225, 135.
2. Ternes, T. A.; Water Res. 1998, 32, 3245.

3. Ternes, T. A.; Stumpf, M.; Mueller, J.; Haberer, K.; Wilken, R.-D.; Servos, M.; Sci. Total Environ. 1999, 225, 81.

4. Hirsch, R.; Ternes, T. A.; Haberer, K.; Mehlich, A.; Ballwanz, F.; Kratz, K.; J. Chromatogr., A 1998, 815, 213.

5. Mulroy, A.; Water Environ. Technol. 2001, 13, 32.

6. Sacher, F.; Lange, F. T.; Brauch, H.; Blankenhorn, I.; J. Chromatogr., A 2001, 938, 199.

7. Ternes, T.; Bonerz, M.; Schmidt, T.; J. Chromatogr., A 2001, 938, 175.

8. Hirsch, R.; Ternes, T.; Haberer, K.; Kratz, K.-L.; Sci. Total Environ. 1999, $225,109$.

9. Kolpin, D. W.; Furlog, E. T.; Meyer, M. T.; Thurman, E. M.; Zaugg, S. D.; Barber, L. B.; Buxton, H. T.; Environ. Sci. Technol. 2002, 36, 1202.

10. Hartig, C.; Storm, T.; Jekel, M.; J. Chromatogr., A 1999, 854, 163.

11. Belfroid, A. C.; Van Der Horst, A.; Vethaak, A. D.; Schäfer, A. J.; Rijs, G. B. J.; Wegener, J.; Cofino, W. P.; Sci. Total Environ. 1999, 225, 101.

12. Ternes, T. A.; Kreckel, P.; Mueller, J.; Sci. Total Environ. 1999, 225, 91.

13. Jonhson, A. C.; Belfroid, A.; Di Corcia, A.; Sci. Total Environ. 2000, 256, 163.

14. Desbrow, C.; Routledge, E. J.; Brighty, G. C.; Sumpter, J. P.; Waldock, M.; Environ. Sci. Technol. 1998, 32, 1549.

15. Baronti, C.; Curini, R.; D‘Ascenzo, G.; Di Corcia, A.; Gentili, A.; Samperi, R.; Environ. Sci. Technol. 2000, 34, 5059.

16. Buser, H.-R.; Poiger, T.; Müller, M. D.; Environ. Sci Technol. 1998, 32, 3449.

17. Steger-Hatmann, T.; Länge, R.; Schweinfurth, H.; Tschampel, M.; Rehmann, I.; Water. Res. 2002, 36, 266.

18. Ternes, T. A.; Hirsch, R.; Environ. Sci Technol. 2000, 34, 2741.

19. Putschew, A.; Wischnack, S.; Tekel, M.; Sci. Total Environ. 2001, 255, 129.

20. Buser, H.-R.; Poiger, T.; Müller, M. D.; Environ. Sci Technol. 1999, 33, 2529.

21. Winkler, H.; Lawrence, J. R.; Neu, T. R.; Water Res. 2001, 35, 3197.

22. Weigel, S.; Kuhlmann, J.; Hühnerfuss, H.; Sci. Total Environ. 2002, $295,131$.

23. Bower, C. K.; Daeschel, M. A.; Int. J. Food Microbiol. 1999, 50, 33.

24. Kümmerer, K.; Chemosphere 2001, 45, 957.

25. Guardabassi, L.; Wong, D. M. A. L.; Dalsgaard, A.; Water Res. 2002, 36, 1955.

26. Guillemot, D.; Curr. Opin. Microbiol. 1999, 2, 494.

27. Mckeon, D. M.; Calabrese, J. P.; Bissonnette, G. K.; Water Res. 1995, 29, 1902.

28. Miranda, C. D.; Castillo, G.; Sci. Total Environ. 1998, 224, 167.

29. Ingerslev, F.; Toräng, L.; Loke, M. L.; Halling-Sorensen, B.; Nyholm, N.; Chemosphere 2001, 44, 865.

30. Loke, M. L.; Ingerslev, F.; Halling-Sorensen, B.; Tjornelund, J.; Chemosphere 2000, 40, 759. 
31. Rabolle, M.; Spliid, N. H.; Chemosphere 2000, 40, 715.

32. Fawell, J. K.; Sheahan, D.; James, H. A.; Hurst, M.; Scott, S.; Water Res. 2001, 35, 1240.

33. Sumpter, J. P.; Toxicol. Lett. 1998, 102-103, 337.

34. Legler, J.; Dennekamp, M.; Vethaak, A. D.; Browwer, A.; Koeman, J. H.; Van der Burg, B.; Murk, A. J.; Sci Total Environ. 2002, 293, 69.

35. Zacharewski, T.; Environ. Sci. Technol. 1997, 31, 613.

36. Kang, I. J.; Yokota, H.; Oshima, Y.; Tzuruda, Y.; Yamaguchi, T.; Maeda, M.; Imada, N.; Tadokoro, H.; Honjo, T.; Chemosphere 2002, 47, 71.

37. Gimeno, S.; Komen, H.; Jobling, S.; Sumpter, J.; Bowmer, T.; Aquat. Toxicol. 1998, 43, 93.

38. Ternes, T. A.; Trends Anal. Chem. 2001, 20, 419.

39. Buser, H.-R.; Müller, M. D.; Environ. Sci Technol. 1998, 32, 188.

40. Xiao, X.-Y.; Mccalley, D. V.; McEvoy, J.; J. Chromatogr., A 2001, 923, 195.

41. Richardson, M. L.; Bowron, J. M.; J. Pharm. Pharmacol. 1985, 37, 1.

42. Halling-Sorensen, B.; Nielsen, S. N.; Lanzky, P. F.; Ingerslev, F.; Lützeft, H. C.; Jorgensen, S. E.; Chemosphere 1998, 36, 357.

43. Jorgensen, S. E.; Halling-Sorensen, B.; Chemosphere 2000, 40, 691.

44. Heberer, T.; Toxicol. Lett. 2002, 131, 5.

45. Chien, Y. H.; Lai, H. T.; Liu, S. M.; Sci. Total Environ. 1999, 239, 81

46. Smith, P.; Samuelsen, O. B.; Aquaculture 1996, 144, 17.

47. Witte, W.; Int. J. Antimicrob. Agents 2000, 14, 321.

48. Kolár, M.; Urbánex, K.; Látal, T.; Int. J. Antimicrob. Agents 2001, 17, 357.

49. Visser, M. R.; Fluit, A. C.; J. Microbiol. Meth. 1995, 23, 105

50. Chee-Sanford, J. C.; Aminov, R. I.; Krapac, I. J.; Garrigues-Jeanjean, N.; Mackie, R. I.; Appl. Environ. Microbiol. 2001, 67, 1494.

51. Andersen, T. J.; Schäfer, T.; Jorgensen, P. L.; Moller, S.; Res. Microbiol. 2001, 152, 823 .

52. Ginzburg, E.; Namias, N.; Brown, M. B.; Suzette, H. S. M.; Cohn, S. M.; Int. J. Antimicrob. Agents 2000, 16, 539.

53. Aburjai, T.; Darwish, R. M.; Al-Khail, S.; Mahafzah, A.; Al-Abbadi, A.; J. Ethnopharmacol. 2001, 76, 39.

54. Wu, R. S. S.; Mar. Pollut. Bull. 1995, 31, 159.

55. Folmar, L. C.; Hemmer, M.; Hemmer, R.; Bowman, C.; Kroll, K.; Denslow, N. D.; Aquatic Toxicol. 2000, 49, 77.

56. Harrison, P. T. C.; Holmes, P.; Humfrey, C. D. N.; Sci. Total Environ. 1997, 205, 97.

57. Castro, C. M. B.; Engenharia Sanitária e Ambiental. 2002, 7, 4.

58. Allen, V.; Matthiessen, P.; Scott, A. P.; Haworth, S.; Feist, S.; Thain, J. E.; Sci. Total Environ. 1999, 233, 5.

59. Patyna, P. J.; Davi, R. A.; Parkerton, T. F.; Brown, R. P.; Cooper, K. R.; Sci. Total Environ. 1999, 233, 211.

60. Taylor, M. R.; Holmes, P.; Duarte-Davidson, R.; Humfrey, C. D. N.; Harrison, P. T. C.; Sci. Total Environ. 1999, 233, 181

61. Hutchinson, T. H; Toxicol Lett. 2002, 131, 75.

62. Solé, M.; Porte, C.; Barceló, D.; Trends Anal. Chem. 2001, 20, 518

63. Schmid, T.; Gonzalez-Valero, J.; Rufli, H.; Dietrich, D. R.; Toxicol. Lett. 2002, 131, 65 .

64. Panter, G. H.; Thompson, R. S.; Sumpter, J. P.; Aquatic Toxicol. 1998, 42, 243.

65. Irwin, L. K.; Gray, S.; Oberdörster, E.; Aquatic. Toxicol. 2001, 55, 49

66. Zerulla, M.; Länge, R.; Steger-Hartmann, T.; Panter, G.; Hutchinson, T.; Dietrich, D. R.; Toxicol. Lett. 2002, 131, 51.

67. Rodger-Gray, T. P.; Jobling, S.; Morris, S.; Kelly, C.; Kirby, S.; Janbakhsh, A.; Harries, J. E.; Waldock, M. J.; Sumpter, J. P.; Tyler, C. R.; Environ. Sci. Technol. 2000, 34, 1521 .
68. Thompson, S.; Tilton, F.; Schlenk, D.; Benson, W. H.; Mar. Environ. Res. 2000, 51,185

69. Gimeno, S.; Komen, A.; Gerritsen, A. G. M.; Bowmer, T.; Aquatic Toxicol. 1998, 47, 77.

70. Jobling, S.; Nolan, M.; Tyler, C. R.; Brighty, G.; Sumpter, J. P.; Environ. Sci. Technol. 1998, 32, 2498.

71. Koger, C. S.; Teh, S. J.; Hinton, D. E.; Mar. Environ. Res. 2000, 50, 201.

72. Larsson, D. G. J.; Adolfsson-Erici, M.; Parkknen, J.; Petersson, M.; Berg, A. H.; Olsson, P.-E., Forlin, L.; Aquatic Toxicol. 1999, 45, 91.

73. Gagné, F.; Blaise, C.; Salazar, M.; Hansen, P. D.; Comp. Biochem. Physiol., Part C: Toxicol. Pharmacol. 2001, 128, 213.

74. Routledge, E. J.; Sheahan, D.; Desbrow, C.; Brighty, G. C.; Waldock, M.; Sumpter, J. P.; Environ. Sci. Technol. 1998, 32, 1559.

75. Rodger-Gray, T.P.; Jobling, S.; Kelly, C.; Morris, S.; Brighty, G.; Waldock, M. J.; Sumpter, J. P.; Tyler, C. R.; Environ. Sci. Technol. 2001, 35, 462

76. Panter, G. H.; Thompson, R. S.; Sumpter, J. P.; Environ. Sci. Technol. 2000, 34, 2756.

77. Van den Bogaar, A. E. V. D.; Stobberingh, E. E.; Int. J. Antimicrob. Agents 2000, 14, 327.

78. Witte, W.; Int. J. Antimicrob. Agents 2000, 14, 321

79. Vree, T. B.; Van der Ven, A. J. A. M.; Van Ewijk-Beneken Kolmer, E. W. J.; Swolfs, A. E. M.; Van Galen, P. M.; Anatdjais-Groenen, H.; J. Chromatogr., B 1994, 658, 327

80. Whitlam, J. B.; Vine, J.; J. Chromatogr. 1980, 181, 463.

81. Hedenmo, M.; Eriksson, B.-M.; J. Chromatogr., A 1995, 692, 161.

82. Farré, M.; Ferrer, I.; Ginebreda, A.; Figueras, M.; Olivella, L.; Tirapu, L.; Vilanova, M.; Barceló, D.; J. Chromatogr., A 2001, 938, 187.

83. Ahrer, W.; Scherwenk, E.; Buchberger, W.; J. Chromatogr., A 2001, 910, 69

84. Lindsey, M. E.; Meyer, M.; Thurman, E. M.; Anal. Chem. 2001, 73, 4640.

85. Golet, E. M.; Alder, A. C.; Hartmann, A.; Ternes, T. A.; Giger, W.; Anal. Chem. 2001, 73, 3632

86. Mol, H. G. J.; Sunarto, S.; Steijger, O. M.; J. Chromatogr., A 2000, 879, 97.

87. Öllers, S.; Singer, H. P.; Fässler, P.; Müller, S. R.; J. Chromatogr., A 2001 $911,225$.

88. Ternes, T. A.; Andersen, H.; Gilberg, D.; Bonerz, M.; Anal. Chem. 2002 74, 3498.

89. Kelly, C.; J. Chromatogr., A 2000, 872, 309.

90. Henschel, K.-P.; Wenzel, A.; Diedrich, M.; Fliedner, A.; Reg. Toxicol. Pharmacol. 1997, 25, 220.

91. Lanzky, P. F.; Halling-Sorensen, B.; Chemosphere 1997, 35, 2553.

92. Migliore, L.; Civitareale, C.; Brambilla, G.; Delupis, G. D. D.; Water Res. 1997, 31, 1801

93. Halling-Sorensen, B.; Chemosphere 2000, 40, 731

94. Wollenberger, L.; Halling-Sorensen, B.; Kusk, K. O.; Chemosphere 2000, 40,723 .

95. Steger-Hartmann, T.; Länge, R.; Schweinfurth, H.; Ecotoxicol. Environ. Saf. 1999, 42, 274

96. Koschorreck, J.; Koch, C.; Rönnefahrt, I.; Toxicol. Lett. 2002, 131, 117.

97. Stuer-Lauridsen, F.; Birkved, M.; Hansen, L. P.; Holten Lützhoft, H.-C.; Halling-Sorensen, B.; Chemosphere 2000, 40, 783.

98. Jones, O. A. H.; Voulvoulis, N.; Lester, J. N.; Water Res. 2002, 36, 5013.

99. Migliore, L.; Brambilla, G.; Cozzolino, S.; Gaudio, L.; Agricul. Ecosyst. Environ. 1995, 52, 103.

100. Boxall, A. B. A.; Blackwell, P.; Cavallo, R.; Kay, R. P.; Tolls, J.; Toxicol. Lett. 2002, 131, 319.

101. Jorgensen, S. E.; Lutzhoft, H. C.; Halling-Sorensen, B.; Ecolog. Model 1998, 107, 63 